\title{
Dexmedetomidine and $S(+)$-ketamine in ischemia and reperfusion injury in the rat kidney ${ }^{1}$
}

\author{
Dexmedetomidina e $S(+)$-cetamina em lesão de isquemia e reperfusão \\ no rim de rato
}

\begin{abstract}
Fabio Geraldo Curtis ${ }^{I}$, Pedro Thadeu Galvão Vianna ${ }^{I I}$, Rosa Marlene Viero ${ }^{\text {III }}$, Paulo Mateus Fiorio ${ }^{\text {IV }}$, Leopoldo Muniz da Silva José Reinaldo Cerqueira Braz ${ }^{\mathrm{II}}$, Cristiano Oliveira ${ }^{\mathrm{VI}}$, Yara Marcondes Machado Castiglia ${ }^{\text {VI }}$
\end{abstract}

\footnotetext{
${ }^{1}$ Research performed at the Experimental Laboratory of Anesthesiology, Botucatu School of Medicine, Sao Paulo State University (UNESP), Brazil. Part of a thesis. Tutor: Yara Marcondes Machado Castiglia. Postgraduate Program on Anesthesiology, Botucatu Medical School, UNESP, Brazil.

${ }^{\mathrm{I}}$ Fellow PhD degree, Postgraduate Program in Anesthesiology, Botucatu Medical School, UNESP, Brazil. Main author. Responsible for conception, design, intellectual and scientific content of the study.

${ }^{\text {II }}$ Full Professor, Department of Anesthesiology, Botucatu Medical School, UNESP, Brazil. Critical revision.

${ }^{\text {III }} \mathrm{PhD}$, Department of Pathology, Botucatu Medical School, UNESP, Brazil. Acquisition and interpretation of data.

${ }^{\text {IV }}$ Graduate student, Botucatu Medical School, UNESP, Brazil. Helped surgical procedures.

${ }^{\mathrm{v}}$ Fellow PhD degree, Postgraduate Program in Anesthesiology, Botucatu Medical School, UNESP, Brazil. Acquisition and statistically interpretation of data.

${ }^{\mathrm{VI}}$ Technician, Department of Anesthesiology, Botucatu Medical School, UNESP, Brazil. Helped surgical procedures.

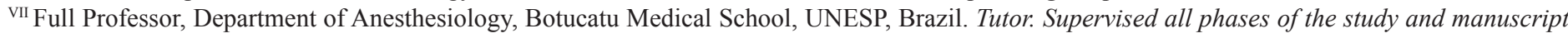
writing.
}

\begin{abstract}
Purpose: To investigate blood creatinine and renal histology in rats anesthetized with $S(+)$-ketamine (keta) or dexmedetomidine (dex) and submitted to kidney ischemia/reperfusion injury (IRI). Methods: Under intraperitoneal (ip) $S(+)$-ketamine, 20 male Wistar rats were divided into two groups (n=10): maintenance with iv $S(+)$-ketamine or dex (keta and dex groups), and submitted to right (R) nephrectomy and left (L) renal artery clamping for $45 \mathrm{~min}$. Blood creatinine was measured before ischemia (T1) and 48h after reperfusion (T2), when L nephrectomy was performed. Histological analysis was performed in all kidneys. Results: Blood creatinine was significantly higher at T2 in both groups, but dex group results were lower than those of keta group. Histological changes: between groups, R kidneys did not differ; there were significant high scores for vascular dilation: keta L kidneys; for vascular congestion, tubular dilation, and necrosis: L kidneys from both groups; for tubular degeneration: keta R kidneys. Conclusion: S(+)-ketamine plus IRI were aggressive to rat kidneys, according to histological changes, and dexmedetomidine may have not totally protected the kidneys from these injuries, despite the better results of blood creatinine.
\end{abstract}

Key words: Dexmedetomidine. Kidney. Reperfusion Injury. Creatinine. Necrosis. Rats.

\section{RESUMO}

Objetivo: Investigar a creatinina sanguínea e histologia renal em ratos anestesiados com $S(+)$-cetamina (ceta) ou dexmedetomidina (dex) e submetidos à lesão de isquemia/reperfusão renal (IR). Métodos: Sob $S(+)$-cetamina intraperitoneal (ip), 20 ratos Wistar machos foram distribuídos em dois grupos (n=10): manutenção com $S(+)$-cetamina ou dexmedetomidina, iv, (grupos ceta e dex), e submetidos à nefrectomia direita $(\mathrm{D})$ e clampeamento da artéria renal esquerda $(\mathrm{E})$ por $45 \mathrm{~min}$. A creatinina sanguínea foi dosada antes da isquemia (T1) e 48h após a reperfusão (T2), quando foi realizada nefrectomia E. Houve análise histológica de todos os rins. Resultados: A creatinina foi significativamente maior em T2 em ambos os grupos, porém menor com a dexmedetomidina. Alterações histológicas: entre grupos, os rins Ds não diferiram; houve escores altos significativos para dilatação vascular: rins Es do grupo ceta; para congestão vascular, dilatação tubular, necrose: rins Es de ambos os grupos; para degeneração tubular: rins Ds do grupo ceta. Conclusão: $S(+)-$ cetamina e IR foram agressivas histologicamente para rins de ratos e a dexmedetomidina pode não ter protegido totalmente os rins dessas lesões, apesar dos melhores resultados de creatinina.

Descritores: Dexmedetomidina. Rim. Traumatismo por Reperfusão. Creatinina. Necrose. Ratos. 


\section{Introduction}

The protective effect of brief periods of artery occlusion and reperfusion against a subsequent prolonged exposure to ischemia and reperfusion (ischemic preconditioning - IPC) has been long demonstrated in the heart and kidney ${ }^{1,2}$. Some intravenous anesthetics have distinctive actions on mitochondrial adenosine triphosphate-sensitive potassium (mitoK(ATP)) channels and these channels play a pivotal role in mediating cardiac preconditioning ${ }^{3}$. The intravenous agent dexmedetomidine is a potent and highly selective $\alpha_{2}$-adrenoceptor agonist that facilitates analgesia and anesthesia in humans. However, it has been demonstrated in a rat model of focal cerebral ischemia that, rather than mimicking IPC protecting the kidney, it reduces total ischemic volume in the cortex ${ }^{4}$. Because IRI may be an event in the perioperative period, and the role of intravenous anesthetics in the course of IRI has not been fully established, research on this protection is welcome. According to the literature, $S(+)$-ketamine did not affect mitoK(ATP) channel activity ${ }^{3,5}$, so the purpose of this study was to assess creatinine level and renal histology in rats anesthetized with $S(+)$-ketamine which received dexmedetomidine and were submitted to kidney IRI.

\section{Methods}

This study was approved by the Institution's Animal Experimentation Ethics Committee. Under $S(+)$-ketamine anesthesia (100 mg/kg-ip), 20 male Wistar rats remained in spontaneous ventilation using a mask with $\mathrm{O}_{2}(1 \mathrm{~L} / \mathrm{min})$. In order to establish the experimental model, a $24 \mathrm{G}$ catheter was inserted into the right internal jugular vein and the left carotid artery. Ringer's lactate solution $(5 \mathrm{~mL} / \mathrm{kg} / \mathrm{h})$ was administered and body temperature was kept at $36^{\circ} \mathrm{C}-38^{\circ} \mathrm{C}$ by placing the rats on a heating pad.

The animals were assigned to two groups $(n=10$ animals each) according to anesthesia maintenance: keta group, intravenous (iv) intermittent $S(+)$-ketamine ( $2 \mathrm{mg} / \mathrm{kg})$; dex group, dexmedetomidine, $1.0 \mu \mathrm{g} / \mathrm{kg}$ iv, during $10 \mathrm{~min}$, and $1.0 \mu \mathrm{g} / \mathrm{kg} / \mathrm{h}$ (Abbott infusion pump Anne, USA). After $20 \mathrm{~min}$ with anesthesia maintenance, all animals underwent median laparotomy, rightsided nephrectomy and clamping of the left renal artery for 45 min. Mean arterial pressure and heart rate were monitored through the catheter in the carotid artery (Datex Engstrom, Finland). After renal artery declamping, the abdomen and neck were closed and ropivacaine $0.5 \%$ was injected into the incisions. The animals were allowed to recover from anesthesia, remaining 48 hours in a controlled-environment room with food and water freely available. Serum creatinine was measured immediately before ischemia (time point T1) and 48 hours after reperfusion (time point T2), under sodium pentobarbital anesthesia $(50 \mathrm{mg} / \mathrm{kg}$, ip) and immediately before left nephrectomy and sacrifice. Full crosssection of the right and left kidneys were processed, the organs were fixed in a Duboscq-Brazil solution $(120 \mathrm{~mL}$ formaldehyde, $30 \mathrm{~mL}$ acetic acid and $2 \mathrm{~g}$ picric acid), for a minimum of 12 hours and a maximum of 36 hours; they were then transferred to $70 \%$ ethanol and sectioned. The sections were stained with hematoxylin and eosin, and identified by a study number not known to the research pathologist who scored the histological changes observed $(0=$ none, $1=$ mild, $2=$ moderate, $3=$ severe $)$.

\section{Statistical analysis}

Statistical analysis was performed with the help of Stata/ SE 9.0 for Windows (Stata Corporation, College Station, Texas, USA). Creatinine values and body weight were expressed by the mean \pm standard deviation. Student's T test was used to compare creatinine values between groups at the same time point. MannWhitney test was used in the comparison between groups at the same time point for histological scores. The Wilcoxon test was used to compare variables between the two studied time points (T1 and T2). Significance level was set at $\mathrm{p}<0.05$.

\section{Results}

Weight $(\mathrm{g})$ (mean $\pm \mathrm{SD}$ ) in the keta and dex groups was $436 \pm 35$ and $375 \pm 43$, respectively $(\mathrm{p}=0.002)$. Blood creatinine $(\mathrm{mg} / \mathrm{dL})$ values at T1 and T2 were, respectively: $0.4 \pm 0.1$ and 5.1 \pm 3.1 in the keta group $(\mathrm{p}=0.005) ; 0.3 \pm 0.1$ and $3.2 \pm 2.8$ in the dex group $(p=0.005)$. In $T 2$, the means are not different $(p=0.16)$ (Figure 1).

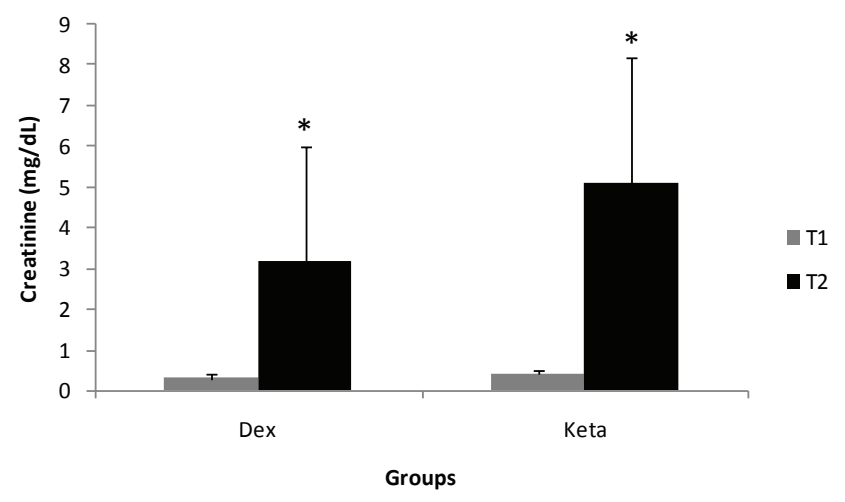

FIGURE 1 - Mean and standard deviation of blood creatinine according to time point $(\mathrm{T} 1=$ before ischemia, and $\mathrm{T} 2=$ after $48 \mathrm{~h}$ of reperfusion $)$ and group. ${ }^{*}=\mathrm{p}<0.05$, so $\mathrm{T} 1<\mathrm{T} 2$. 
In all groups, histological analysis (Figure 2) revealed no statistical difference among the right kidneys.
A

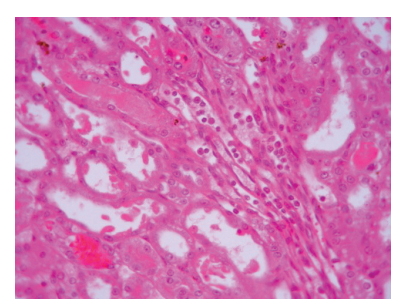

B

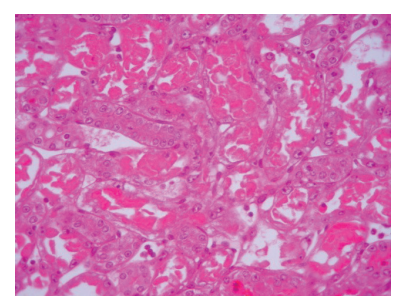

FIGURE 2 - Hematoxylin eosin-stained histological sections (40X) of rat left kidneys after ischemia-reperfusion injury. Anesthesia was induced with $S(+)$-ketamine, and maintained with $S(+)$-ketamine (keta group) or dexmedetomidine (dex group). A. Vascular dilation and congestion. B. Intense necrosis.

Vascular dilation (Table 1) was observed in right and left kidneys of all groups, but in the keta group the scores were higher in the left than in the right kidneys $(\mathrm{p}<0.05)$.

TABLE 1 - Scores of vascular dilation (VD) and vascular congestion (VC) in the right (R) and left (L) kidney according to group, keta or dex.

\begin{tabular}{|c|c|c|c|c|c|c|}
\hline \multirow[b]{2}{*}{ Group } & \multicolumn{2}{|c|}{ VD } & $\mathrm{p}$ & \multicolumn{2}{|c|}{$\mathrm{VC}$} & $\mathrm{p}$ \\
\hline & $\mathrm{R}$ & $\mathrm{L}$ & & $\mathrm{R}$ & $\mathrm{L}$ & \\
\hline
\end{tabular}

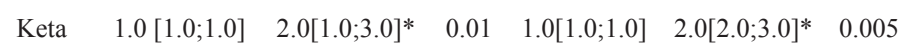

$\operatorname{Dex} \quad 1.0[1.0 ; 2.0] \quad 2.0[1.0 ; 2.0] \quad 0.21 \quad 1.0[0.0 ; 1.0] \quad 1.5[1.0 ; 2.0]^{*}$

\begin{tabular}{lllll}
\hline $\mathrm{p}$ & 0.30 & 0.30 & 0.16 & 0.27 \\
\hline
\end{tabular}

Data are reported as median $\left(25^{\text {th }}\right.$ and $75^{\text {th }}$ percentile $) . *$ median value of left $(\mathrm{L})$ and right ${ }^{\circledR}$ kidney significantly different $(\mathrm{p}<0.05)$; \# median value significantly lower among groups $(\mathrm{p}<0.05)$.

The keta and dex groups had the same degree of vascular congestion (Table 1) and the left kidneys of both groups had higher scores than right kidneys $(\mathrm{p}<0.05)$. Tubular dilation (Table 2 ) scores in the keta and dex groups were higher in the left than in the right kidney $(\mathrm{p}<0.05)$, and there was no significant difference between the results of these groups. Although the keta group showed less tubular degeneration (Table 2) in the left than in the right kidney, there were no statistical differences between groups. In the keta and dex groups, left kidneys had equally significant higher scores of necrosis ( $p>0.05$ ) (Figure 3 ).
TABLE 2 - Scores of tubular dilation (TD) and tubular degeneration (TDe) in the right ${ }^{\circledR} .01$ and left $(\mathrm{L})$ kidney according to group.

\begin{tabular}{lcccccc}
\hline & \multicolumn{2}{c}{$\mathrm{TD}$} & $\mathrm{p}$ & \multicolumn{2}{c}{$\mathrm{TDe}$} & $\mathrm{p}$ \\
\cline { 2 - 7 } Group & $\mathrm{R}$ & $\mathrm{L}$ & & $\mathrm{R}$ & $\mathrm{L}$ & \\
\hline Keta & $1.0[1.0 ; 1.0]$ & $3.0[2.0 ; 3.0]^{*}$ & 0.002 & $1.0[1.0 ; 1.0]^{*}$ & $0.0[0.0 ; 1.0]$ & 0.01 \\
& & & & & & \\
\hline Dex & $1.5[1.0 ; 2.0]$ & $3.0[2.0 ; 3.0]^{*}$ & 0.002 & $1.0[1.0 ; 1.0]$ & $1.0[0.0 ; 2.0]$ & 0.57 \\
\hline $\mathrm{p}$ & 0.13 & 0.70 & & 0.32 & 0.08 & \\
\hline
\end{tabular}

Data are reported as median $\left(25^{\text {th }}\right.$ and $75^{\text {th }}$ percentile). $*$ median value of left $(\mathrm{L})$ and right $(\mathrm{R})$ kidney significantly different $(\mathrm{p}<0.05)$; \# median value significantly lower among groups $(\mathrm{p}<0.05)$.

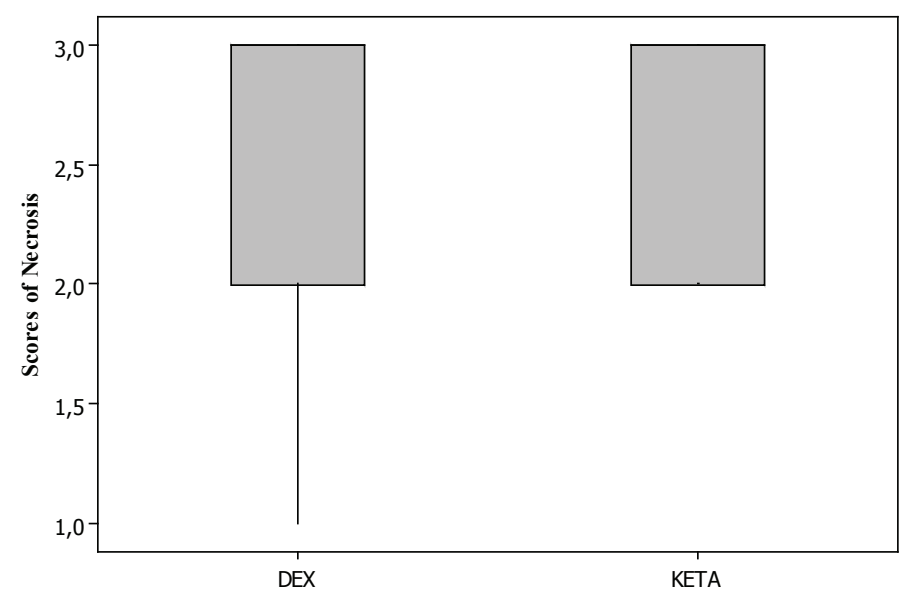

FIGURE 3 - Scores of necrosis in the left kidney (data reported as median, $25^{\text {th }}$ and $75^{\text {th }}$ percentile), 48 hour after ischemia-reperfusion, according to group (dex and keta); $\mathrm{p}=0.90$; Dex $=$ Keta.

\section{Discussion}

Renal injury associated with ischemia-reperfusion results from a dynamic process involving the vasculature and tubules in a complex interaction whereby events modulating the vasculature will alter oxygen and nutrient delivery to the epithelial cell, and the injured epithelial cell will respond by producing autocrine factors that will affect its own survival and paracrine factors that will affect the vasculature. There is a complex activation of signaling cascades resulting in hemodynamic changes, leukocyte accumulation and cytoskeletal breakdown, loss of cell polarity, apoptosis and necrosis, desquamation of viable and necrotic cells, tubular obstruction and backleak ${ }^{6}$.

Serum creatinine is not a reliable biomarker during acute changes in kidney function. Indeed, it does not accurately depict kidney function until steady-state equilibrium has been reached, which may require several days ${ }^{7}$. According to Moran et al. ${ }^{8}$, 
an abrupt decrease in glomerular filtration rate is followed by a slow rise in creatinine over 48 to 72 hours. The limitations to the use of blood creatinine as a marker of kidney function are due to differences in age, sex, dietary intake, muscle mass, and clearance by tubular secretion that can result in significant variation in baseline serum creatinine values ${ }^{9,10}$. In addition, certain factors can reduce the accuracy of serum creatinine assays, and lead to artifactual increases in serum creatinine levels ${ }^{9}$. Assuming that our experimental model is homogeneous, dex group had most reduced serum creatinine levels two days after reperfusion than keta group.

Delbridge et al. ${ }^{11}$ reported that the temperature of the animal during the ischemic period of IRI significantly affects injury severity, and that the use of a homeothermic heating blanket led to an increase in creatinine level by day three. In our study, the animals were kept between normothermia-mild hypothermia, which explains the increased serum creatinine.

Jolkkonen et al. ${ }^{4}$ administered dexmedetomidine to rats as an intravenous bolus of $3 \mu \mathrm{g} / \mathrm{kg}$ over $5 \mathrm{~min}$ followed by a $120 \mathrm{~min}$ infusion of $3 \mu \mathrm{g} / \mathrm{kg} / \mathrm{h}$. After occlusion of the middle cerebral artery, they observed that dexmedetomidine decreased total ischemic volume in the cortex, and was associated with some minor degree of hyperglycemia and hypotension besides being safer regarding kidney toxicity. The protein kinase C (PKC) is important for IPC as it activates intracellular signaling pathways providing organ protection - the opening of sarcolemal and mitochondrial ATPsensitive potassium channels ( sarcK $_{\text {ATP }}$ and mitoK ${ }_{\text {ATP }}$, respectively) - and yet through genetic transcription, promoting the protective cellular protein synthesis. An investigation of alternative signaltransduction pathways has demonstrated that $\alpha_{2 \mathrm{~B}}$-adrenoceptor stimulates PKC activity and inositol triphosphate production in kidney distal convoluted tubule cells. This fact could be responsible for the same cell protection conferred by IPC ${ }^{12,13}$.

Kocoglu et $a l .{ }^{14}$ studied the role of dexmedetomidine on renal histological alterations after IRI. They found normal glomeruli and slight edema of the tubular cells, and according to them dexmedetomidine could reduce the renal injury caused by IRI of the kidney. The $\alpha_{2}$-adrenoceptor agonist was administered ip, in single dose of $100 \mu \mathrm{g} / \mathrm{kg}$, at the starting time of reperfusion, and the rats had been anesthetized previously with ketamine, $50 \mathrm{mg} / \mathrm{kg}$, and xylazine, $20 \mathrm{mg} / \mathrm{kg}$, ip. Time of ischemia was 60 minutes and the rats were sacrificed after 45 minutes of reperfusion. Differently, we infused dexmedetomidine continuously, as in clinical practice, and after ip $S(+)$-ketamine only, and we studied the kidneys after $48 \mathrm{~h}$ of reperfusion. So, our results are from kidneys with more accentuated alterations and they are not totally comparable to those of Kocoglu et al. ${ }^{14}$.
In this study, $S(+)$-ketamine was the induction anesthetic of choice because it could facilitate the administration of dexmedetomidine without interfering with study results ${ }^{15}$. In a renal histology study, after acute hemorrhage of $30 \%$ of volemia, it was found that rats receiving sodium pentobarbital or $S(+)$ ketamine had hypotension from hemorrhage with $S(+)$-ketamine, and that the score of histological changes was higher in the $S(+)$ ketamine group ${ }^{16}$. Vascular dilation and congestion, as well as tubular dilation and degeneration in the right kidney were observed in all our study groups. The fact that these changes were seen even in keta group suggests that $S(+)$-ketamine caused these alterations. The association of IRI with $S(+)$-ketamine and dexmedetomidine also provoked vessel changes. Tubular degeneration was also caused by $S(+)$-ketamine as indicated by the high scores seen in the right kidneys that did not undergo ischemia. Our results demonstrate that $\mathrm{S}(+)$-ketamine plus the experimental model of IRI used here was aggressive to rat kidneys, and dexmedetomidine did not protect the kidneys from these aggressions.

\section{Conclusion}

Our results demonstrate that $\mathrm{S}(+)$-ketamine plus the experimental model of IRI used here was aggressive to rat kidneys, according to histological changes, and dexmedetomidine may have not totally protected the kidneys from these injuries, despite the better results of blood creatinine. However, further studies should be conducted to elucidate the role of venous anesthetic agents in IRI.

\section{References}

1. Murry CE, Jennings RB, Reimer KE. Preconditioning with ischemia: a delay of lethal cell injury in ischemic myocardium. Circulation. 1986;74:1124-36.

2. Zager RA, Baltes LA, Sharma HM, Jurkowitz MS. Responses of the ischemic acute renal failure kidney to additional ischemic events. Kidney Int. 1984;26:689-700.

3. Zaugg M, Lucchinetti E, Spahn D, Pasch T, Garcia C, Schaub MC. Differential effects of anesthetics on mitochondrial $\mathrm{K}_{\text {ATP }}$ channels activity and cardiomyocyte protection. Anesthesiology. 2002;97:1523.

4. Jolkkonen J, Puurunen K, Koistinaho J, Kauppinen R, Haapalinna A, Nieminen L, Sivenius J. Neuroprotection by the $\alpha_{2}$-adreneceptor agonist, dexmedetomidine, in rat focal cerebral ischemia. Eur J Pharmacol. 1999;372:31-6.

5. Müllenheim J, Frässdorf J, Preckel B, Thämer V, Schlack W. Ketamine, but not $S(+)$-ketamine, blocks ischemic preconditioning in rabbits hearts in vivo. Anesthesiology. 2001;94:630-6.

6. Bonventre JV, Weinberg JM. Recent advances in the pathophysiology of ischemic acute renal failure. J Am Soc Nephrol. 2003;14:2199210.

7. Nguyen MT, Devarajan P. Biomarkers for the early detection of 
acute kidney injury. Pediatr Nephrol. 2008;23:2151-7.

8. Moran SM, Myers BD. Course of acute renal failure studied by a model of creatinine kinetics. Kidney Int. 1985;27:928-37.

9. Bagshaw SM, Gibney TN. Conventional markers of kidney function. Crit Care Med. 2008;36:S152-8.

10. Shemesh O, Golbetz H, Kriss JP, Myers BD. Limitations of creatinine as a filtratiom marker in glomerulopathic patients. Kidney Int. 1985;28:830-8.

11. Delbridge MS, Shrestha BM, Raftery AT, El Nahas AM, Haylor JL. The effect of body temperature in a rat model of renal ischemiareperfusion injury. Transplant Proc. 2007;39:2983-5.

12. Gesek FA. Alpha2-adrenergic receptors activate phospholipase $\mathrm{C}$ in renal epithelial cells. Mol Pharmacol. 1996;50:407-14.
13. O'Rourke B. Evidence for mitochondrial $\mathrm{K}+$ channels and their role in cardioprotection. Circ Res. 2004;94:420-32.

14. Kocoglu H, Ozturk H, Ozturk H, Yilmaz F, Gulcu N. Effect of dexmedetomidine on ischemia-reperfusion injury in rat kidney: a hitopathologic study. Ren Fail. 2009;31:70-4.

15. Zaugg M, Lucchinetti E, Spahn D, Pasch T, Garcia C, Schaub MC. Differential effects of anesthetics on mitochondrial $\mathrm{K}_{\mathrm{ATP}}$ channels activity and cardiomyocyte protection. Anesthesiology. 2002;97:1523.

16. Rusafa Neto E, Vianna PT, Viero RM, Módolo NS, Ganem EM, Braz RC, Castiglia YM. Influence of $\mathrm{S}(+)$-ketamine analgesia in renal intraoperative ischemia. Histological study in rats. Acta Cir Bras. 2006;21:242-6.

\section{Correspondence:}

Yara Marcondes Machado Castiglia

Faculdade de Medicina - UNESP

Depto. Anestesia

Caixa postal 530

18618-970 Botucatu - São Paulo Brasil

Phone/Fax: (55 14)3811-6222

yarac@fmb.unesp.br
Conflict of interest: none Financial source: CAPES and PIBIC/CNPq

Received: November 10, 2010

Review: January 13, 2011

Accepted: February 17, 2011 